
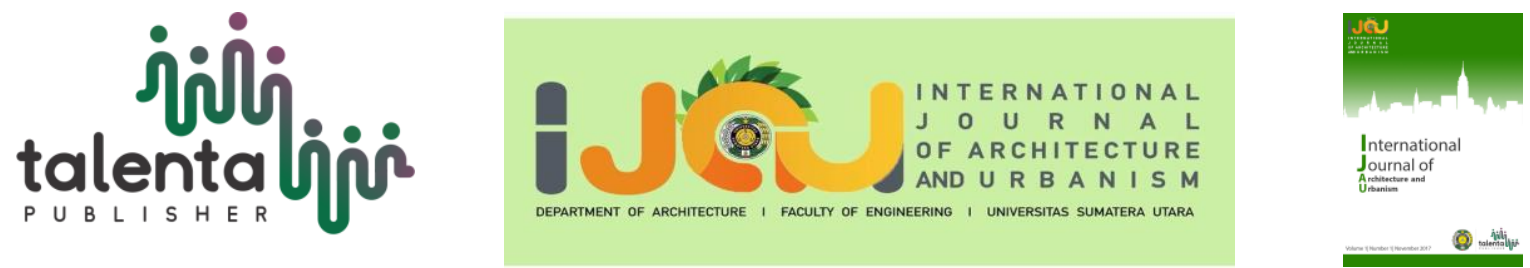

\title{
Rejuvenation of City Gateway as the Identity of Medan
}

\author{
Dwi Lindarto Hadinugroho ${ }^{1}$, Eunice Ananda Putri Matondang ${ }^{\text {* }}$ \\ ${ }^{I}$ Department of Architecture, Faculty of Engineering, Universitas Sumatera Utara, Medan, Indonesia
}

\begin{abstract}
As a developing city, Medan carries out a significant role in establishing the identity and image of the city and the development of the surrounding cities and districts. One effort to establish the identity and image of the city can be created through the existence of city gates that can produce a plot, rhythm, and balance for the city bounded. The gate of Medan City has not succeeded in becoming a city gate that meets the needs needed by migrants who pass through the city gate area. This study will address the problems discovered at the Medan City gate in Binjai, Tanjung Morawa, Tembung, and Pancur Batu and relate them to the rejuvenation of the city area through revitalization methods in supporting Metropolitan Mebidangro. The research aims to analyze predetermined variables, namely elements of the city image, namely path, edge, district, nodes, and landmark. For this reason, a qualitative descriptive study was carried out, which was realized through observation and interviews and also documentation studies. The results of the research obtained from this study can be used as a reference and solution to find out the problems that exist int the area around Medan City gate and also give functional supports to develop the area around Medan City.
\end{abstract}

Keyword: city gate, identity, rejuvenation

Received 01-04-2020 | Revised 01-05-2020 | Accepted 15-05-2020

\section{Introduction}

Medan City Gate has not succeeded in becoming a welcoming, aesthetic, and educative city gate. The gate of the city of Medan, which is conceptualized as a tourist attraction with distinctive architecture and represents a heritage, can be an asset that shows the identity and image of the city of Medan. This research will increase the problem discovered at the gate of Medan City and relate it to the redeveloping process of the city area through the revitalization method in order to support the metropolitan city concept. In the context of regional rejuvenation in support of Metropolitan Mebidangro, a revitalization that links the city image theory and genius loci aims to restore the vitality and vitality of the city based on local wisdom, which will be realized through regional rejuvenation. As follows, through this research, an output of the design model will be obtained based on five elements of the city image based on local wisdom.

\footnotetext{
*Corresponding author at: Department of Architecture, Faculty of Engineering, Universitas Sumatera Utara, Jalan Perpustakaan Gedung J07, Medan 20155, Indonesia

E-mail address: eunice.matondang@gmail.com
} 


\section{Literature Review}

Rejuvenation of urban areas represents the rearrangement of areas built up of urban areas that have experienced degradation in environmental quality, degradation of area functions, and adjustments of urban areas to urban development plans. According to Djoko Sujarto in the book Some Understanding of Physical Planning (1985), city rejuvenation is defined as the process of redeveloping a part of the city area that has been built to increase productivity and use of parts of the city area. Urban rejuvenation can also be interpreted as an activity to control, organize, and rehabilitate or rebuild a part of the city that has been damaged to accommodate activities that are consistent with existing city plans [1].

According to Lynch (1960), about the image of the city, there are five main elements which are typically used to build their visual image of an urban area, namely the path, edge, district, node, and landmarks. These five main elements are enough to do a useful visual survey of the distinctive shape of a city. A place that is formed later will produce a space that has a characteristic as an identity that describes the place [2].

Schulz (1979) also stated that a "place" is a room that has a distinctive characteristic that is the result of the form of objects that have shape, structure, and color. Put differently, a place can be interpreted as a space that has been interpreted by an activity that produces an atmosphere in, so that the place possesses a physical form that can be optimized through the human senses (not abstract). This place is also related to interactions between humans and activities that take place in that place and will eventually form an identity, character, and genius loci [3].

\section{Methodology}

This research implements a descriptive qualitative method. Moleong (2000) defines quality methodology as a research process that produces descriptive data in the form of written or oral words from people and observable behavior. Descriptive research represents a form of research aimed at describing existing phenomena [4].

To discover the prime object that will represent the focus of observation, researchers use several indicators to obtain data related to paths, edges, districts, nodes, and landmarks. Also, researchers additionally used interview methods, the results of which will be delivered descriptively as effectively as literature studies (Table 1).

Table 1 Research Variable

\begin{tabular}{|c|c|c|c|c|c|}
\hline Variable & Path & Edge & District & Node & Landmark \\
\hline \multirow{4}{*}{ Indicator } & - Types and Functions & - Types & & - Orientation & - Orientation \\
\hline & - Shape & and & - Characteristic & - Types and & - Types and Functions \\
\hline & - Element & Functions & - Activity & Functions & - Position \\
\hline & - Activity & - Activity & & - Activity & - History and Meaning \\
\hline
\end{tabular}




\section{Result and Discussion}

The prime location of the research is in the pivotal points of the City Gate of Medan, which borders Binjai, Tanjung Morawa, Tembung, and Pancur Batu, which are influenced by Malay and Batak Architecture styles, both Toba and Karo. The strategic location of the gate will represent a driver of city branding to improve the economy of the local community.

Based on the consistent results of field observations, the results of qualitative data analysis and literature study, there are two types of design concepts for Medan City rejuvenation gates that can be applied in rejuvenation efforts at city gate locations that are the object of research, including Landmark Gateway and District Gateway. Landmark Gateway is a model of the city gate with the main object "marker" in the form of a monument and also serves as a marker of orientation in the gate area. A city gate with a landmark gateway concept is intended for a city gate area bordering a river, vacant land and an area that is usually only traversed by people entering and exiting through the city gate whereas District Gateway is a model of city gates where the constituent elements are the conditions of the city gates themselves. The concept of a district gateway is for city gates in the local commercial area which is closely related to culture and social interaction formed by the community, both migrants and residents of the area so that the area can produce a characteristic that can be an orientation for the city gate area itself.

In the concept of designing a landmark gateway at this location, the prime object is the city gate itself. The city gate monument or welcome gate serves as a marker when entering the area or out of the Medan-Binjai City gate area (Figure 1).

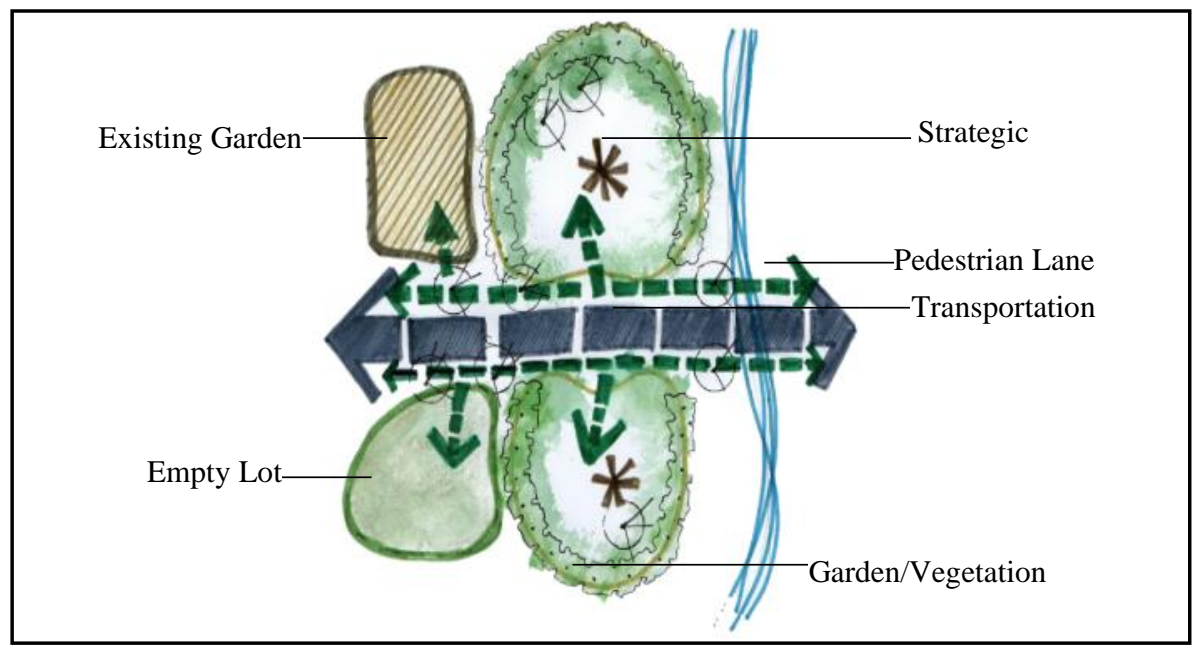

Figure 1 Pra-Design Concept of Medan-Binjai City Gate

The concept of landmark gateways in this area is also to emphasize the boundaries of the region and act as attractive nodes and describe the identity of this region. Formation of the quite good city gate monument by taking the characteristics of the Malay area but still impressed naive so that the shape of the monument was shown by taking the form of roofs, colors, and Malay culture so that it becomes more elegant and beautiful (Figure 2). 


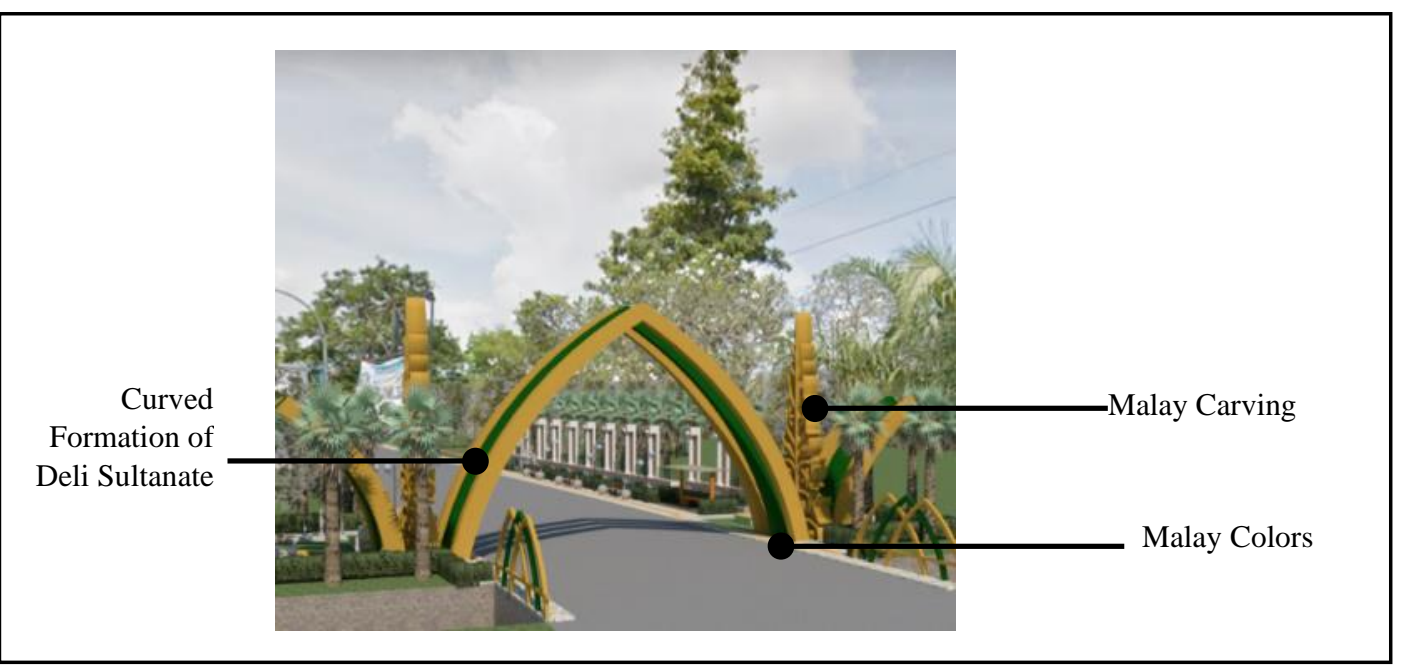

Figure 2 Gate Pra-Design Concept

Also, the lanes at this location, especially the main lane on Jalan Banda Aceh, which is crowded with many vehicles, both private and public vehicles and heavy vehicles such as trucks across the city is sufficient. Unfortunately, the need for pedestrian lines as pedestrian circulation access is inadequate. Therefore, a pedestrian path will be designed so that it can meet the needs of its users. Also, the pedestrian path is added with additional elements like chairs and bollards (Figure 3).

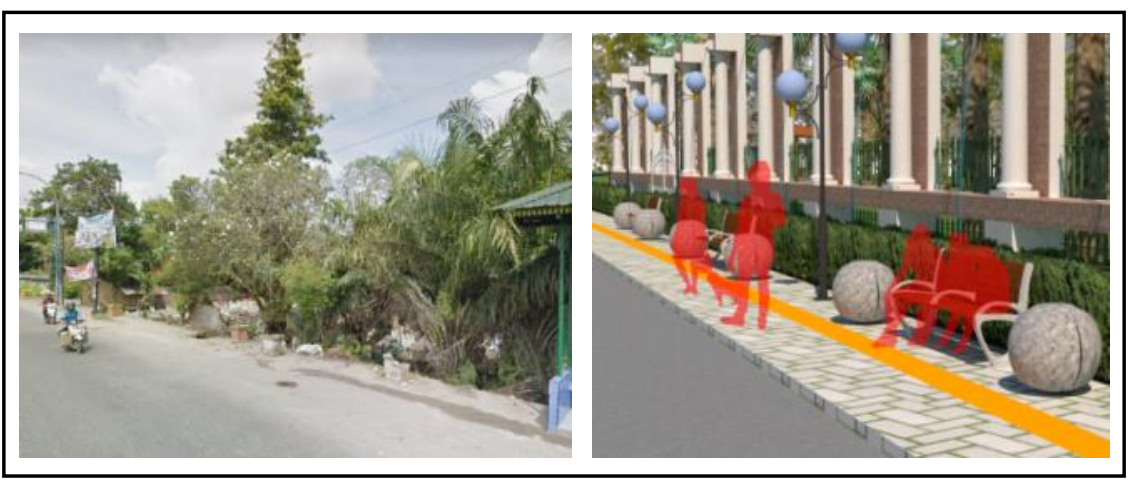

Figure 3 Existing (left) and Pedestrian Lane Concept (right)

The surrounding area that was designed in this area is in the form of green space for hedges and trees as well as bridge formations that take on the distinctive shape and color of Malays to clarify the boundaries of the gate area of Medan-Binjai City.

The concept of a district gateway that will be applied in this area will be realized through the restructuring of the city gate area without losing its original function, where the city gate is not only a gate to the arrival gate, but can be a destination when entering the city gate area. The main points in the pre-design concept are the provision of locations for street vendors who are still not arranged in the pedestrian path, the arrangement of the socialization space equipped with supporting facilities, and the city gate as one of the orientation markers other than the area itself (Figure 4). 


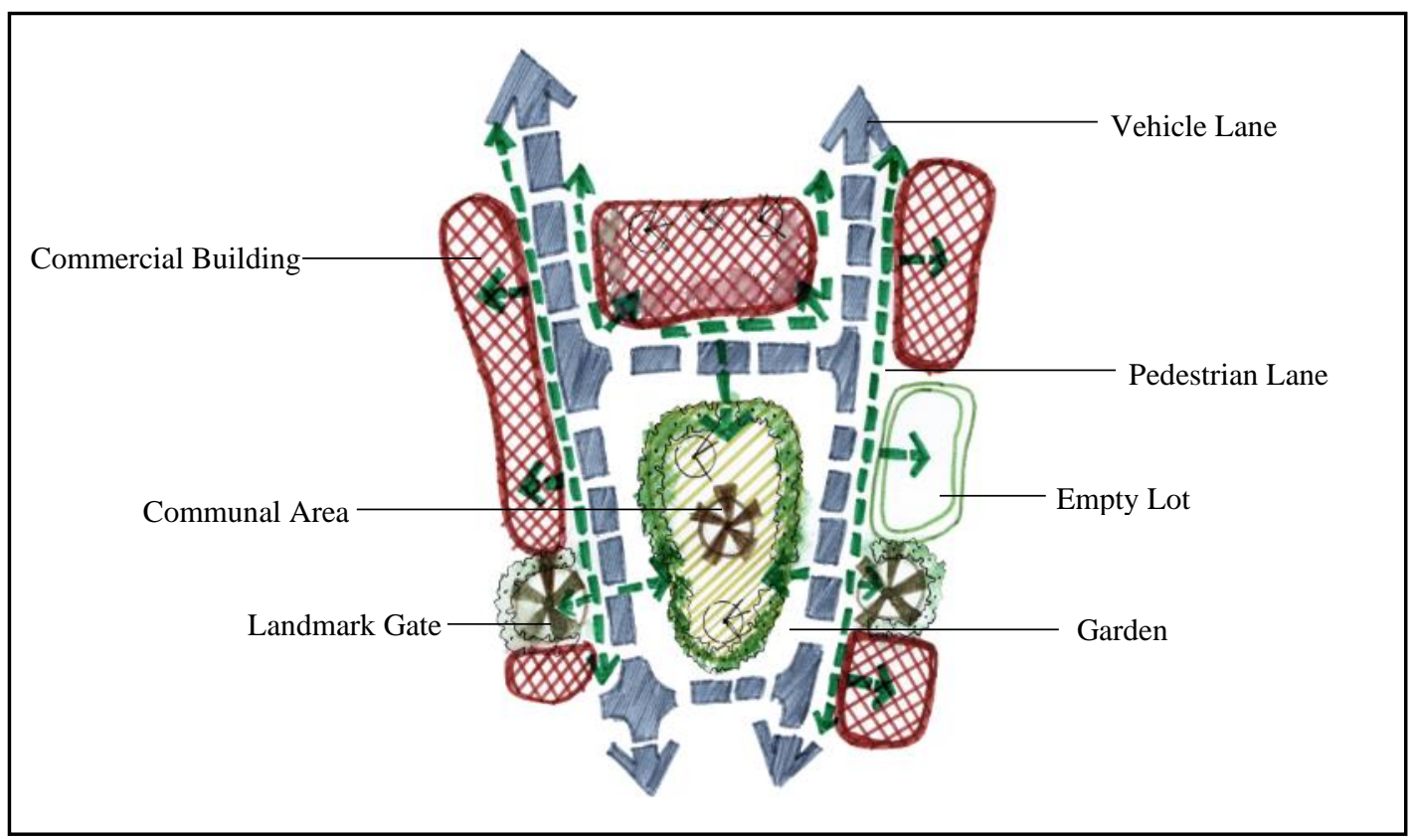

Figure 4 Pra-Design Concept of Medan-Pancur Batu City Gate

Structuring into a messy street vendor, especially those in the pedestrian lane, so that through the social arrangement of the prime location, the Medan-Pancur Batu city gate area is no longer bound by slums (Figure 5).

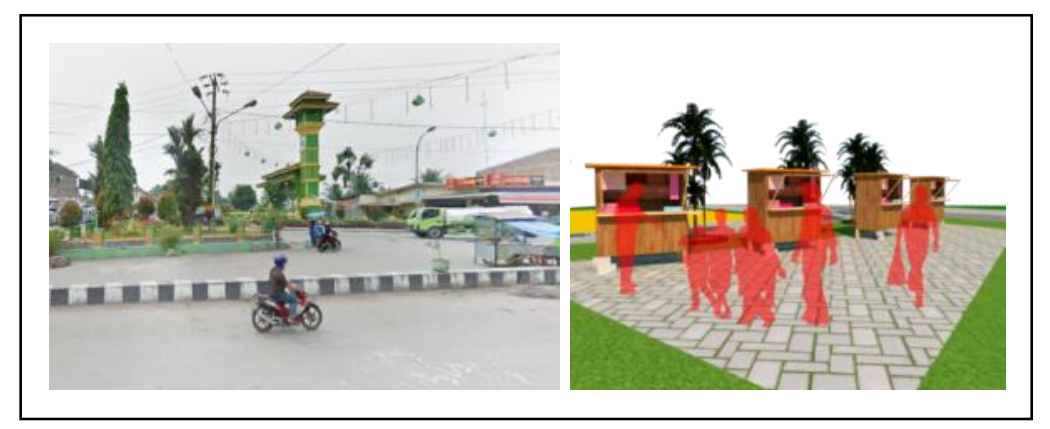

Figure 5 Existing Street Vendor (left) and Street Vendor Pra-Design Concept (right)

The concept of structuring the location of the city gate area arises from a literature review and comparative study of the city gate area at Kanazawa Station, where the existence of pedestrian lines and grocery stores that have existed for a long time was simply uneliminated but reorganized so that it became an attractive destination when entering the area.

Communal areas at this location are quite numerous and varied, such as meeting roads, parks, intersections, commercial areas, which are the gathering points so on. Therefore, in the rejuvenation of this element is done is structuring to maximize the vitality of the gathering point itself, like the arrangement of the park in the middle of the location of the gate and a place to wait for public transportation to become an organized and attractive communal area (Figure 6). 


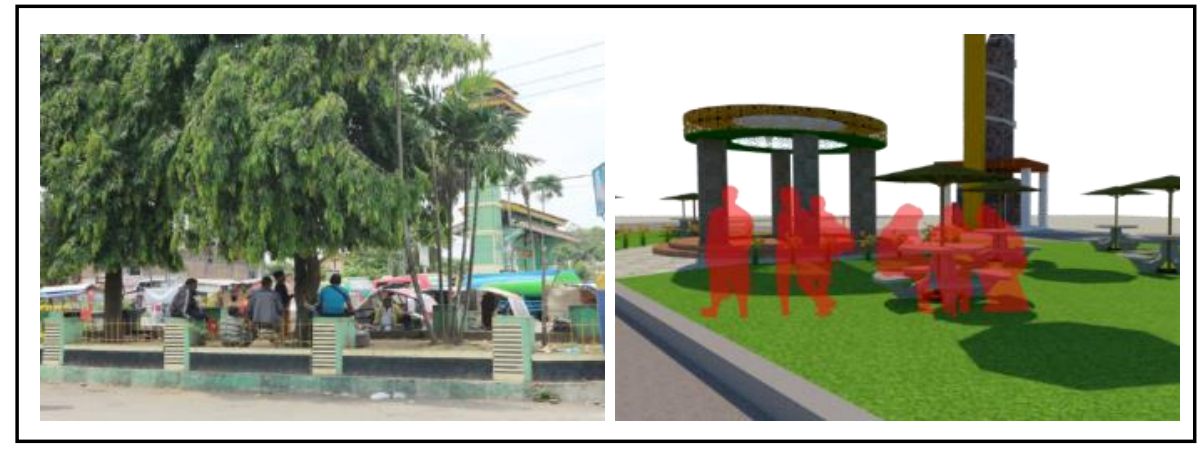

Figure 6 Existing Communal Area (left) and Communal Area Pra-Design Concept (right)

The existence of the monument is also one of the essential points that need to be considered to organize the city gate area. The existence of the existing Medan-Pancur Batu city gate in terms of the position that is invisible (on the left side of the direction of Medan City) and less attractive. On this basis, then a pre-designed monument of the city gate will be made, which equally responds to the existing condition of the pedestrian path so that the monument can support the role of the city gate as a marker and orientation and identity of the city itself (Figure 7).

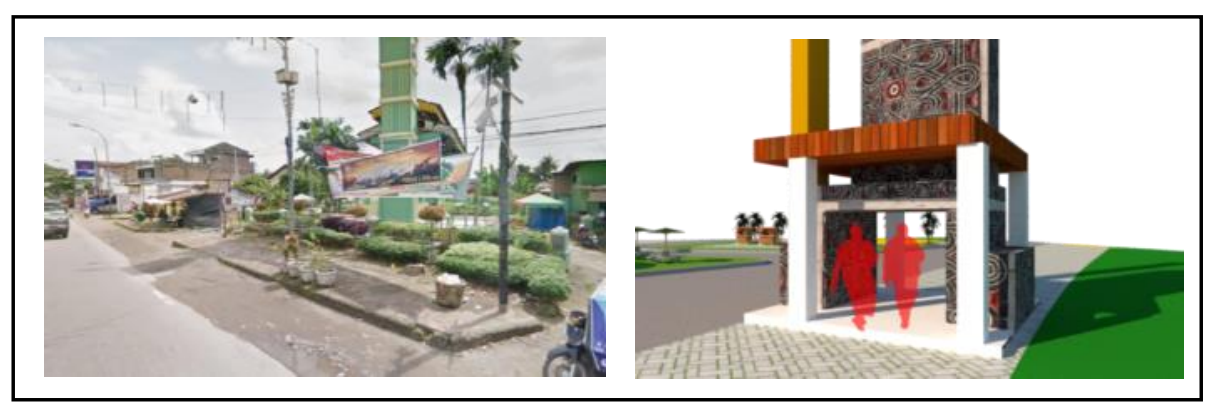

Figure 7 Existing Gate Sculpture (left) and Gate Sculpture Pra-Design Concept (right)

\section{Conclusion}

The architectural design concept of the city gate rejuvenation model is to use two types of city gate concepts adapted to the existing conditions at the city gate location to be designed, namely the use of the landmark gateway concept at the city gate location bordering rivers, vacant land, and areas that are usually only traversed by people entering and exiting through the city gate and the concept of a district gateway at the location of the city gate located in the local commercial area closely related to the culture and social interaction formed by the community both migrants and residents of the gate area. The use of street furniture and vegetation can also add a physical attraction to the gate area itself.

\section{Acknowledgment}

The results of this research are expected to be useful for local governments to find out the problems and dedicated to the community to educate insight into the identity of Medan City gate. 


\section{REFERENCES}

[1] J. Sujarto, Beberapa Pengertian Perencanaan Fisik, Jakarta: Bhrata Karya Aksara, 1985.

[2] K. Lynch, The Image of the City, Cambridge: MIT Press, 1960.

[3] N.-S. Christian, Genius Loci: Towards a Phenomenology of Architecture, New York: Rizzoli, 1979.

[4] L. J. Moleong, Metode Penelitian Kualitatif, Bandung: PT Remaja Rosdakarya, 2000. 